\title{
COMUNICAÇÃO DIRIGIDA NAS ESCOLAS
}

\section{Recursos adequadamente selecionados podem melhorar a transmissão de informações nas instituições escolares, reduzindo os ruídos na comunicação}

Em todos os tempos, desde as primitivas civilizações, a criatura humana, por imposição da sua própria natureza, sempre procurou encontrar os melhores caminhos para o seu progresso e desenvolvimento, a partir, inclusive, da satisfação de suas necessidades individuais de vida em comum com os seus semelhantes, de cooperação mútua e solidariedade, de harmonia social e, até, de aprimoramento moral.

Esses condicionamentos da vida, inerentes à natureza humana, que sempre existiram como expressão de sobrevivência e do desejo do homem de progredir, crescer e evoluir, certamente, também, abrangiam meios próprios e recursos adequados às circunstâncias, com o sentido de criar e facilitar condições favoráveis à aquisição de conhecimentos entre os membros das diversificadas comunidades que se formavam em torno dos grupos familiares.

Não seria estranho admitir que esses recursos já integrassem as diferentes fases do processo comunicativo, rudimentares a princípio, porém mais do que aptos e suficientes para possibilitar a troca de informações, necessárias ao próprio desenvolvimento.

Ora, se o processo de comunicação existe desde as primitivas épocas da história, conhecidas ou desconhecidas, infere-se que o ser humano tenha desenvolvido esforços pessoais e construtivos para alcançar seus objetivos de progresso, tendo como ponto de partida os mesmos princípios que regem a comunicação dos nossos dias.

Esses princípios mantiveram-se constantes e praticamente imutáveis, não se registrando variações significativas na sua essência e conteúdo. A rigor, esses princípios foram se transmitindo de geração a geração por um processo natural de comunicação, mas, com o passar dos tempos, adquiriram corpo e se estruturaram com tal magnitude que ocupam, hoje, um espaço próprio entre os importantes ramos do conhecimento.

As Ciências da Comunicação, atingindo o inegável estágio de sofisticação do mundo globalizado, haveriam de incorporar-se e adaptar-se aos novos padrões sociais e ao próprio processo evolutivo. Vêm daí as novas estruturas das diferentes áreas da Comunicação e, no interior destas, os desdobramentos das matérias mais diretamente ligadas à transmissão de informações $\mathrm{e}$, conseqüentemente, vinculadas à elaboração e ampliação de conhecimentos.

A comunicação dirigida, como a própria designação sugere, há de ser um corpo de conhecimentos direcionados, num primeiro plano, àqueles que se propõem a ministrá-los e transmiti-los por dever de ofício.

\section{O AUTOR}

\section{Waldir Ferreira}

Professor Doutor do Departamento de Relações Públicas, Propaganda e Turismo da ECA-USP. E-mail: waldir@usp.br 
Nesta categoria, incluem-se as escolas ou instituições de ensino, que se impõem a obrigação de coordená-los dentro de rigores técnicos e científicos, a fim de alcançar um melhor e total aproveitamento dos instrumentos dos quais é dotada. Num segundo plano, a comunicação dirigida visa a um público previamente identificado, para quem a mensagem ou conteúdo da comunicação se dirige e que se constitui na essência dos seus objetivos.

\section{COMUNICAÇÃO DIRIGIDA}

Podemos dizer que "comunicação dirigida é o processo que tem por finalidade transmitir ou conduzir informações para estabelecer comunicação limitada, orientada e freqüente com determinado número de pessoas homogêneas e identificadas"'.

A comunicação dirigida é uma forma de comunicação social e humana com quatro elementos: um emissor que seleciona, codifica e emite informações, por meio de um canal (veículos escritos orais aproximativos e auxiliares) a um receptor (público determinado, que capta, decodifica e seleciona) para que haja feedback (retorno da informação) $)^{2}$.

Nas escolas, a comunicação dirigida não trata das comunicações unilaterais como os jornais, televisão, rádio e outros veículos de comunicação de massa.

A rigor, a comunicação dirigida sempre envolve as comunicações bilaterais, por meio das quais a transferência de informa- ções está sujeita a dois tipos de redes, quatro níveis e quatro direções.

Redes: formal e informal. A rede formal é aquela que segue o organograma da instituição de ensino, controlada pela hierarquia funcional. São ordens, instruções, notas, relatórios etc., constituindo o sistema formal de comunicação da escola. Rede informal é aquela que surge das relações sociais entre professores, estudantes e funcionários e não é controlada. Ela é variável, dinâmica, indo e vindo através das linhas orgânicas e mudando sua direção rapidamente.

Niveis: intrapessoal é a comunicação subjetiva do emissor, isto é, onde realmente se inicia o processo de comunicação. Interpessoal é a comunicação com outros indivíduos ou grupos. Organizacional trata da comunicação que se estabelece nas relações da escola com suas unidades administrativas e destas com os respectivos públicos. Tecnológico é o nível da comunicação que se processa com o emprego de equipamentos adequados e próprios das técnicas modernas.

Direções: Fluxo ascendente é a transmissão de informações dos subordinados para os superiores. Trata-se de relatórios, prestação de contas, desempenho de alunos etc. Fluxo descendente é a transmissão de informações dos superiores para os subordinados. Tratam de política, objetivos, normas, procedimentos etc. Fluxo transversal é o fluxo de comunicação entre as pessoas situadas no mesmo nível hierárquico. Visa a um trabalho em conjunto e fornece as informações necessárias ao bom desempenho de cada setor. Fluxo extra-organizacional é o fluxo que sai da escola para os diferentes públicos: correspondência, eventos, relatórios etc.

1. FERREIRA, Waldir. Comunicação dirigida: instrumento de relações públicas. In: KUNSCH, Margarida M. Krohling (org.). Obtendo resultados com Relações Públicas. São Paulo: Pioneira, 1997. p.71-81.

2. Esse também é o esquema que representa o sistema da comunicação como transmissão de informação elaborado pelos teóricos da Teoria Informacional e da Teoria Matemática da Comunicação. Cf.: COHN, Gabriel. Comunicação e indústria cultural. São Paulo: Nacional, 1975. Parte II. (N. Ed.) 


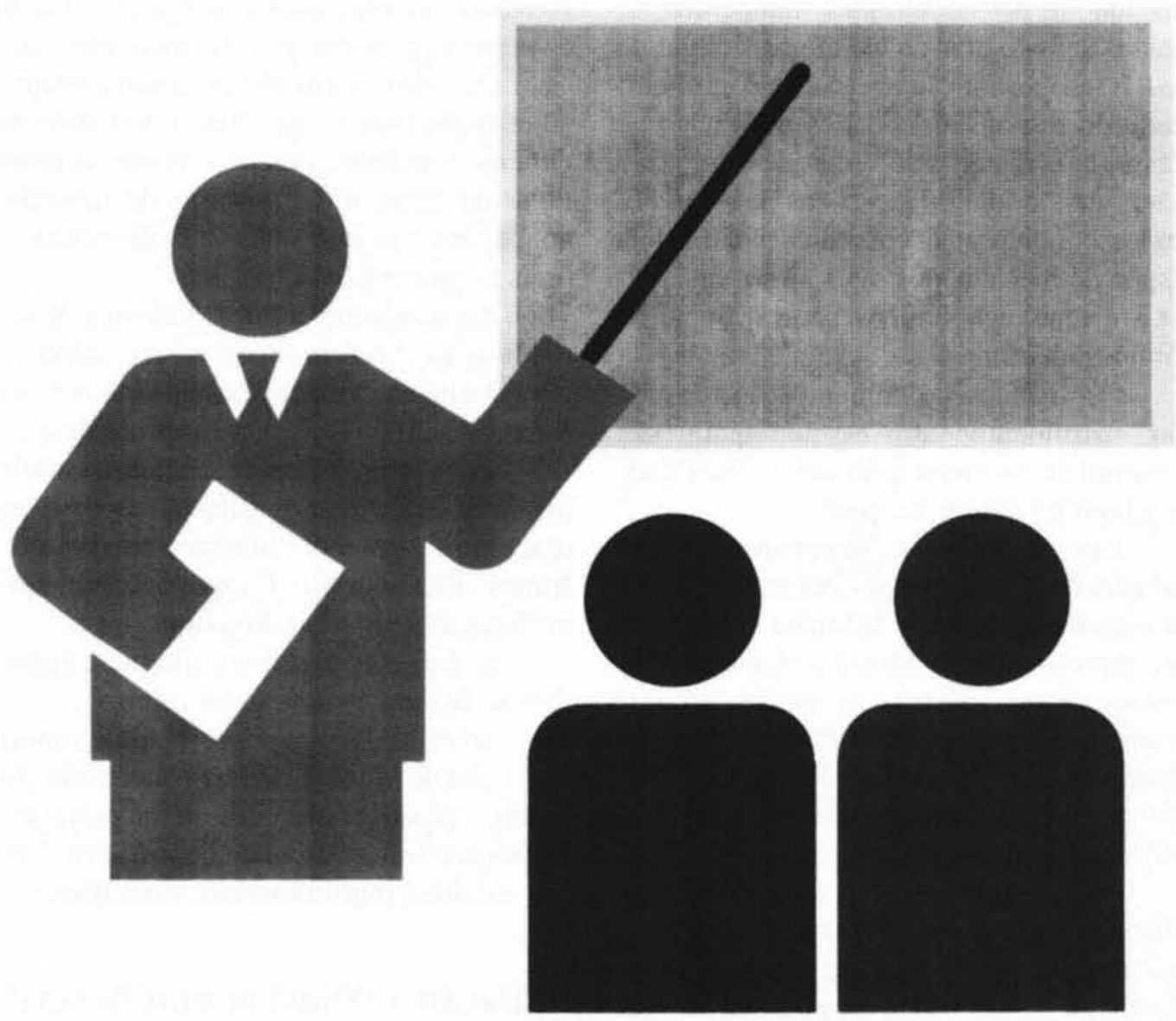

No processo de transferência de informação, o que mais preocupa o responsável pela comunicação são as barreiras ou ruídos que a dificultam. Estas barreiras podem ser divididas, de maneira muito ampla, em psicológicas (dificultam as comunicações interpessoais), sociológicas (agem nos processos de comunicações entre grupos) e técnicas (uso indevido ou incompleto do canal de comunicação). As barreiras ou ruídos surgem dos preconceitos, meios, experiências individuais, estados fisiológicos e emocionais, atenção, confusões entre fatos e opiniões, inferências e observações, vocabulário etc.

À comunicação dirigida cabe a elaboração da mensagem eficiente, eficaz e apta a

produzir os efeitos desejados no público receptor. Evidentemente, sob este enfoque, enquadram-se todos os requisitos e elementos essenciais, que a integram e a caracterizam. A fonte produtora da mensagem é a escola, o aluno, o professor, enfim, a administração escolar; o receptor é o público que se pretende constituir e estimular por meio do veículo escolhido.

Essa mensagem, bem planejada e estruturada, e a escolha adequada do veículo de comunicação dirigida proporcionarão um feedback mais rápido que, por sua vez, permite uma análise imediata dos efeitos produzidos.

Esse aspecto representa uma das grandes vantagens oferecidas pela comunicação 
dirigida em detrimento da comunicação de massa. Sem cogitar do exame conceitual de massa, é oportuno lembrar que o primeiro passo do responsável pela comunicação de massa é caracterizado pela determinação dos grupos e identificação dos públicos. $\mathrm{E}$, nessas condições, a comunicação dirigida dispõe de mecanismos mais aptos, mais diretos e mais econômicos para alcançar os públicos identificados.

Os veículos de comunicação dirigida são instrumentos através dos quais são transmitidas as mensagens com a finalidade de atingir o público receptor.

Em que pese a despreocupação deste trabalho em classificar os diferentes veículos ou entrar no mérito da natureza e conteúdo das expressões utilizadas, é conveniente dar destaque à sua validade, na medida em que possa corresponder às expectativas de quem planeja e coordena a execução. Todo este instrumental resume-se em veículos escritos, orais, aproximativos e auxiliares.

Os veículos escritos são a correspondência (interna e externa), a mala direta, os manuais de funcionários, de organização, de identidade visual e outros; publicações que se destinem a um público determinado ou parte deste: relatórios, boletins, informativos etc.

Os veículos orais são o telefone, intercomunicador, radiocomunicação, alto-falante etc.

Entende-se por veículos aproximativos aqueles que permitem qualquer aproximação física entre os públicos e a escola: congressos, reuniões de informação ou discussão, conferências, aulas, palestras, conversas, discursos, entrevistas, treinamentos; visitas à escola e às diferentes instituições; feiras ou mostras de livros, ciências etc., praça de esportes, auditório, biblioteca, museu, ambulatório, estacionamento e demais dependências usadas pelos públicos; serviços prestados à comunidade, donativos, bolsas de estudos, patrocínios, concursos, brindes.

Os veículos auxiliares, como a própria adjetivação indica, permitem o seu aproveitamento imediato pois, na verdade, ocupam lugar de suma importância e de inúmeras aplicações nas suas comunicações escritas, orais e aproximativas.

Ao se enumerarem os veículos de comunicação dirigida auxiliar, estabelece-se uma distinção entre os recursos visuais, auditivos e audiovisuais propriamente ditos.

a) recursos visuais: álbum seriado, bandeiras, cartazes, diafilmes, diapositivos, diagramas, desenho animado, exposição, filmes, flanelógrafo, fotografias, gravuras, gráficos, imantógrafo, logotipo.

b) recursos auditivos: alarmes, apitos, discos, fita magnética, sirene, sino.

c) recursos audiovisuais: filme sonorizado, fita de vídeo, diafilme sonorizado (fotografia positiva, em filme para projeção), sequiência sonorizada de diapositivos (cromo, eslaide), multimídia em computador.

\section{RELAÇÕES COM O PÚBLICO-ALVO}

Nas escolas, as relações com as pessoas são procedimentos da administração escolar, sistematicamente estruturados, os quais se destinam a manter, promover, orientar e estimular a formação de públicos, por meio da informação e da comunicação dirigida, a fim de tornar possível a coexistência dos interesses visados pela instituição de ensino e pelo público-alvo.

O conceito pode ser desdobrado a partir de uma visão sistêmica, compreendendo os componentes básicos de quaisquer atividades ou empreendimentos, a saber: natureza (administrativa), finalidade (reciprocidade de interesses), objeto (formação de públicos) e meios (informação e comunicação). 
Adaptando o nosso conceito a estes componentes, ele se completa com a análise conceitual e exame crítico dos elementos que o compõem.

\section{Natureza: administrativa}

“... procedimentos da administração escolar, sistematicamente estruturados..."

A ciência da administração, após a elaboração teórica dos fenômenos observados, deverá adotar as providências que lhe são peculiares - planejar, organizar, dirigir e controlar - para que sejam alcançados os fins desejados.

Nesse sentido, iniciarão os procedimentos que se adaptem às circunstâncias de cada caso, que, no seu conjunto, são distribuídos pelas diferentes unidades da administração escolar. Essas unidades administrativas compõem a escola, já devidamente estruturada, na qual pode se incluir um órgão de relações com o público-alvo.

\section{Finalidade: reciprocidade de interesses}

“... a fim de tornar possível a coexistência dos interesses visados pela instituição de ensino e pelo público-alvo."

A coexistência dos interesses visados exprime, de pronto, a correlação dos interesses comuns, a conciliação dos interesses recíprocos, a compreensão mútua; infere, de um lado, o interesse do público, caracterizado pelas considerações racionais, pelas opiniões e, de outro lado, o interesse particular da escola, traduzido nos objetivos que procura alcançar.

\section{Objeto: formação de públicos}

"... que se destinam a manter, promover, orientar e estimular a formação de públicos..."

A discussão, por si só, sugere, de imediato, a existência de uma questão controvertida, em que o interesse material ou intelectual das pessoas envolvidas se fazem presentes na solução da controvérsia.

Ao responsável pelas relações com os públicos cabe promover a constituição desse público, levantando a questão e/ou colhendo dados sobre pontos controvertidos, no sentido de atingir as suas finalidades, ou seja, a conciliação do interesse público com o interesse da escola.

\section{Meios: informação e comunicação}

"... por meio da informação e da comunicação dirigida..."

Fixados os interesses da escola, o responsável pela comunicação ou o possível órgão de relações com o público-alvo, dentre outros da estrutura organizacional, é acionado para cumprir o seu objetivo e a sua finalidade.

Assim, previstas as possibilidades, estabelecido o plano de ação e coordenados todos os dados coletados e disponíveis, há que se pôr em prática os elementos teóricos idealizados pelo responsável pela comunicação ou órgão competente.

A viabilidade de concretização das hipóteses levantadas e previstas fica na dependência direta do instrumental que compõe a comunicação dirigida. Aliás, a corporificação de qualquer idéia só se torna possível e se aperfeiçoa mediante o emprego de instrumentos específicos e adequados fornecidos pela comunicação. Aí reside a importância desse ramo do conhecimento a comunicação e, em particular, a comunicação dirigida.

Assim, se as técnicas constituem subsídios bastantes e de grande valia para a aplicação prática, não menos importante é a atuação do responsável pela comunicação no manuseio das informações, para que as relações delas decorrentes possam satisfazer, a contento, as pessoas nelas envolvidas. 


\section{COORDENAÇÃO DA COMUNICAÇÃO}

O homem, desde os primeiros tempos da vida em comum com os seus semelhantes, sentiu a grande necessidade de se ligar e se organizar, atribuindo, a um ente qualquer, autoridade ou poder no sentido de regular a conduta humana. Essas imposições, certamente, estariam sujeitas a uma escala de comando, impondo-se a fixação das diferentes atribuições em cada setor da sociedade.

Simultaneamente, e dadas as exigências cada vez maiores da expansão social e tecnológica, as funções foram subdivididas e atribuídas a pessoas diferentes, com o objetivo de viabilizar o trabalho coletivo. Em consequiência, surgiu um conjunto de atividades interligadas, com a denominação de administração que, posteriormente, passou a ser um ramo do extenso sistema do conhecimento humano.

A administração tem como finalidade fundamental a coordenação de esforços em grupo para as funções de planejar, organizar, dirigir e controlar, o que significa unir e harmonizar todos os atos a serem praticados de forma coerente e ordenada.

A partir destes princípios fundamentais da administração é que a habilidade do responsável pela comunicação se faz presente, não só sob o aspecto de economia e eficiência do seu trabalho, como também sob o prisma de desenvolvimento, controle e atuação de toda a equipe necessária à respectiva execução.

A comunicação dirigida nas escolas compreende o desempenho de funções as mais variadas, distribuídas a pessoal técnico e especializado, mas tem a responsabilidade de todo o desenvolvimento do processo de execução inteiramente concentrado nas mãos do coordenador. A este, para alcançar os objetivos últimos do seu trabalho, cabe, necessariamente, realizar e promover a harmonia e interdependência dos especialistas, considerados individualmente ou em conjunto. Quaisquer que sejam essas funções específicas, ao coordenador compete a supervisão geral e a adaptação, umas às outras, das diferentes atividades que compõem a comunicação dirigida.

À coordenação ou supervisão geral, todavia, não chega ao ponto de se atribuir responsabilidade direta e total da elaboração e realização dos trabalhos programados. Compete-lhe, apenas, o controle e avaliação dos resultados obtidos. Evidentemente, embora não tenha a obrigação de conhecer todos os aspectos técnicos de cada atividade de comunicação dirigida, a rigor, deve dispor de noções básicas daquelas funções, para que todos os elementos funcionem recíproca e harmonicamente.

O coordenador pode e deve dividir as funções e, independentemente da assistência de terceiros, a ele estão afetos os resultados finais. Por isso, o sucesso ou fracasso das diferentes atividades depende da habilidade de bem coordenar.

Pondere-se que a instituição de ensino, ao confiar a execução de um trabalho de comunicação, pressupõe a existência do senso de responsabilidade daquele a quem está sendo atribuída a respectiva tarefa, caracterizada por propósitos honestos, dignidade e respeito mútuo.

Eis que, em relação à equipe de trabalho, o coordenador deverá conciliar todos os serviços, a fim de que se concretizem e se tornem realidade as intenções e os aspectos subjetivos dos interessados.

Para tanto, ao coordenador se impõem certos atributos de personalidade e aptidão, 
como talento, arte, cultura geral, alto senso de comunicação, trabalho em equipe e, principalmente, imediatismo na tomada de decisões. Em outras palavras, o coordenador deve ter discernimento para ir ao encontro daquilo que o interessado deseja.

A despeito dessas qualidades vinculadas à atividade, o coordenador deve também ser firme, enérgico e intransigente em relação à sua autoridade e conhecimentos específicos. A sua orientação e as sugestões do pessoal envolvido não podem ser desvirtuadas em favor da eventual criatividade dos interessados.

Se as relações com os diferentes públicos estão situadas no campo da comunicação, atuando na área da administração escolar, infere-se que o responsável daquela atividade é um administrador da comunicação e, conseqüentemente, deve cumprir e observar os princípios fundamentais dessas áreas.

\section{NOVAS TECNOLOGIAS E A COMUNICAÇÃO DIRIGIDA}

O mundo moderno experimenta profundas e aceleradas transformações decorrentes do progresso científico e do inevitável desenvolvimento de novas tecnologias.

Relembrando e recorrendo às previsões de Alvin Toffler, autor da obra A terceira onda ${ }^{3}$, não há como se omitir a opinião daquele escritor, quando afirma que durante milênios vivemos a "primeira onda ou sociedade agrícola", período em que a "fazenda" era a unidade geradora de empregos e recursos financeiros - fase de predomínio da agricultura. Com a Revolução Industrial, inicia-se a "segunda onda ou sociedade industrial", onde a "fábrica" passa a ser a uni- dade produtora de recursos econômicos e a principal fonte de empregos.

No entanto, o avanço da tecnologia, da informática, da robótica e da telecomunicação apresenta um quadro novo: o trabalho físico e intelectual do homem é substituído pelas inovações técnicas, proporcionando o aparecimento da "terceira onda ou sociedade da informação".

É na "terceira onda" que os veículos de comunicação de massa, tão poderosos na "segunda onda", começam a ser desmassificados para dar lugar aos veículos de comunicação dirigida. $\mathrm{Na}$ "terceira onda", então, a comunicação dirigida passa a ocupar um espaço próprio e peculiar, delimitado por seu campo de atuação e alcance.

As reuniões e determinados eventos que sempre foram realizados em recintos fechados, para um número limitado de pessoas, hoje são realizados para um número bem maior de pessoas espalhadas por todo o Brasil, graças à tecnologia da EMBRATEL - Empresa Brasileira de Telecomunicações.

Os diferentes arquivos e acervos, as correspondências e contatos com o Brasil e o mundo foram agilizados com os computadores.

$\mathrm{O}$ videotexto, as fitas de vídeo, o facsímile, a terceira dimensão, sem dúvida substituíram com grande vantagem diferentes veículos anteriormente usados.

Não há massificação da comunicação dirigida, mas os jornais, as revistas, o rádio e a televisão - principais meios de comunicação de massa da segunda onda - estão, cada vez mais, especializando-se e utilizando-se da comunicação dirigida para atingirem determinados públicos, ou parte de seus públicos. 
A comunicação dirigida não é uma área nova que começa a ser estudada, mas um aspecto da comunicação, cuja importância só agora está sendo reconhecida. Afinal, a comunicação dirigida é um meio ou instrumental que as escolas sempre empregaram para manter, promover, orientar e estimular a formação de seus diferentes públicos.

A função administrativa de relações com o público-alvo não se sobrepõe ao igual caráter relevante que lhe emprestam os veículos de comunicação, através dos quais é atingida a meta perseguida. Se a estruturação sistemática da escola ocupa posição doutrinária de realce, não menos importante é todo instrumental fornecido pela comunicação dirigida.

Nessa linha de pensamento, a comunicação dirigida se apresenta visível e inconteste na ida e volta das informações, como mecanismo ou instrumental a ser acionado, para estabelecer e manter compreensão mútua entre os interessados: de um lado, o público formado e, de outro, a escola pública ou privada.

Naturalmente, a coordenação se faz essencial e necessária, devendo ser estimu-

Resumo: A partir do conceito de comunicação dirigida, calcado no pressuposto da comunicação como transmissão de informação, o autor estabelece redes, niveis e direçōes em que o fluxo de informação pode operar de maneira coordenada e eficaz. Trata dos veículos de comunicação dirigida de que a instituição escolar pode fazer uso, bem como das estratégias administrativas para a aproximação com seu público-alvo.

Palavras-chave: comunicação dirigida, escola, transmissão de informação, público-alvo lada em qualquer instituição, porque é o ordenamento sincronizado de todas as unidades administrativas.

Fixados estes parâmetros, a correlação proposta entre administração, escola e comunicação encontra justificativa nas fases que compreendem o processo de relações com o público-alvo, entre as quais se enfatiza o emprego dos meios e de todo o instrumental fornecido pela comunicação, o qual se insere o amplo programa de informação.

Convém lembrar que o responsável pela transferência de informações não é um mero executante da comunicação, mas um administrador da comunicação, que emprega os instrumentos fornecidos pela comunicação dirigida para atingir os fins a que se propõe. Ele é parte integrante e peça fundamental da administração escolar, com íntima vinculação ao instrumental de que deve dispor para levar a bom termo o exercício das suas funções.

Com estas observações, pode-se afirmar que a eficácia desses relacionamentos está na dependência do uso adequado de um sistema eficiente de comunicação. De nada valerá o esforço do responsável pela comunicação, se a troca de informações estiver em desarmonia com a realidade dos fatos, idéias e opiniões.

Abstract: Based on the directed communication concept, supported on the assumption of communication as a transmitter of information, the author establishes networks, levels and directions that the information flown may operate through in a coordinated and efficient manner. These are the directed means of communication that a school may use, as well as administrative strategies to come closer to its target public.

Key words: Directed communication, school, information transmission, target public 